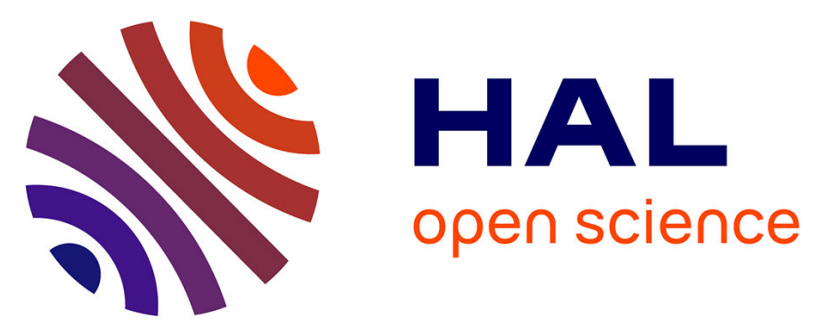

\title{
A Framework Based on Predictive Maintenance, Zero-Defect Manufacturing and Scheduling Under Uncertainty Tools, to Optimize Production Capacities of High-End Quality Products
}

Paul-Arthur Dreyfus, Dimitrios Kyritsis

\section{To cite this version:}

Paul-Arthur Dreyfus, Dimitrios Kyritsis. A Framework Based on Predictive Maintenance, Zero-Defect Manufacturing and Scheduling Under Uncertainty Tools, to Optimize Production Capacities of HighEnd Quality Products. IFIP International Conference on Advances in Production Management Systems (APMS), Aug 2018, Seoul, South Korea. pp.296-303, 10.1007/978-3-319-99707-0_37 . hal02177852

\section{HAL Id: hal-02177852 \\ https://hal.inria.fr/hal-02177852}

Submitted on 9 Jul 2019

HAL is a multi-disciplinary open access archive for the deposit and dissemination of scientific research documents, whether they are published or not. The documents may come from teaching and research institutions in France or abroad, or from public or private research centers.
L'archive ouverte pluridisciplinaire HAL, est destinée au dépôt et à la diffusion de documents scientifiques de niveau recherche, publiés ou non, émanant des établissements d'enseignement et de recherche français ou étrangers, des laboratoires publics ou privés. 


\title{
A framework based on predictive maintenance, zero-defect manufacturing and scheduling under uncertainty tools, to optimize production capacities of high-end quality products
}

\author{
Paul-Arthur Dreyfus ${ }^{1,2}$, Dimitrios Kyritsis ${ }^{1}$ \\ ${ }^{1}$ EPFL, ICT for Sustainable Manufacturing, EPFL SCI-STI-DK, Station 9, CH-1015 \\ Lausanne, Switzerland \\ ${ }^{2}$ EPFL, Artificial Intelligence Laboratory, EPFL IC IINFCOM LIA Station 14, \\ CH-1015 Lausanne and \\ EPFL \\ Paul.dreyfus@epfl.ch
}

\begin{abstract}
Nowadays exploiting the full potential of the humongous amount of data that manufactures can produce with their production means is a real challenge. Moreover, increasing production capabilities without large investments is a recurring objective for them. To reach this objective, many different strategies are in development i.e. zero-defect manufacturing, predictive maintenance and scheduling algorithms which deal with high uncertainty. In the end, they will all be implemented in industry. Their joined implementation in the industry is however missing a coherent framework that would allow to merge those different solutions. This paper proposes an approach that combines those three deeply interconnected technologies to bring a clean solution that significantly improves production capacity. This paper present the approach giving an idea of the possibilities and opportunities of the presented solution.
\end{abstract}

Keywords: Predictive maintenance, tuning assistant, zero-defect manufacturing, automatic scheduling agent, scheduling under uncertainty, industry 4.0 .

\section{Introduction and State of the art}

Like the three past major industrial changes, the worldwide industry is undergoing an in-depth mutation, leading to so called 4th industrial revolution or Industry 4.0.. During the past few years, different countries around the world presented the development of smart factories as one of their long-term strategies such as the 'Industry 4.0' in Germany or the 'industrial Internet' in the United States.

Up to now, different solutions have been studied, and more or less successfully implemented, to augment production capabilities such as predictive maintenance or automatic scheduling agent. On that vein, predictive maintenance is one of 
the recent trends that implements machine learning techniques to tackle real industrial issues. This solution is very popular and even big services companies such as IBM provide predictive maintenance services. Our approach includes this solution, not as a whole, but as a component. Scheduling is the heart of a production floor and optimized scheduling is a major enabler for improvements in production capability. In this context, including automatic scheduling tool with predictive maintenance is a very interesting approach. As demonstrated by Liu et al. [10], those two components are tightly linked. Another approach known as zero defect manufacturing regroups different solutions which aim to reduce the number of rejected products as well as increasing the production capabilities. Raabe et al.[12] used one of those solution to show that it is possible and valuable to identify problems in the production line which lead to rejected products. The approach proposed in this study aims at creating one solution combining predictive maintenance, automatic scheduling and zero defect manufacturing.

\section{Framework and approach}

Firstly, all three technologies which are tuning assistant, predictive maintenance and automatic scheduling are presented. Then the framework, which link them is explained.

\subsection{Tuning assistant for zero defect manufacturing}

Every machine needs to be tuned. The belief which describes machines that have to be tuned only one time to produce forever is far from reality. It is even more true for high-end industry with products aiming at tiny tolerances and with very accurate quality control, where small perturbations such as temperature change or small tools wearing can force to re-tune the machine. The keystone of a good production floor is, therefore, the group of machine operator and technician that control and tune machines. Actually, the tools that help them to tune machines are very basic. This is why product changeover can sometimes take weeks. A tuning assistant is a tool which is very effective to tune and help tuning the machine. It is a machine learning algorithm that will help technicians to produce conform pieces. First, it tunes automatically the machine when it is needed and second it gives critical information to technicians, helping them to tune the machine when it cannot be done automatically. This technology enter in one category of the zero defect manufacturing paradigm called : "Early Malfunction detection and analysis" [4]. Therefore, the machine is faster to tune during product changeover. It is more robust to well-known changes thanks to the algorithm that tunes the machine in real time. But also if there is a problem that cannot be automatically repaired by the tuning assistant, the production can quickly be stopped and the technician informed, so that the number of nonconform products is minimized and the machine re-launched in production as quickly as possible. 
There is not a lot of documentation about this solution, Bufardi et al. [3] provides an example of real-time defect correction for non-conventional production machines, electrical discharge machining, using only two types of sensors. But it is to some extent hard to find publications on conventional production machines. However some publications propose interesting framework for tuning assistant [15]. A lot of Horizon 2020 project are actually working to find practical solutions to apply Zero defect manufacturing, like Z-fact0r or FOCUS.

In the approach presented, the tuning assistant is the first component. It is made of two independent blocks. The first one, i.e. "Estimation block" takes as input all the measurements from machine's sensors, the geometric tolerance measurement, the quality control feedback and possible alerts from technicians. It also receives conclusions of the tuning assistant working in the machine that did the previous operation, for instance, if the actual tuning assistant is working for the finishing stage, it will receive feedback from the tuning assistant working for the machining stage. This estimation block outputs first a vector of estimations describing the probability that the machine needs to be tuned, and second a vector of estimation of the time that those tuning are expected to take. Those outputs will go to the scheduling algorithm that will take the decision on either to tune or not the machine. The second block called "Tuning block" receives as input a tuning request explaining the type of tuning that need to be done. It will either do it automatically or help the technician to do it efficiently.

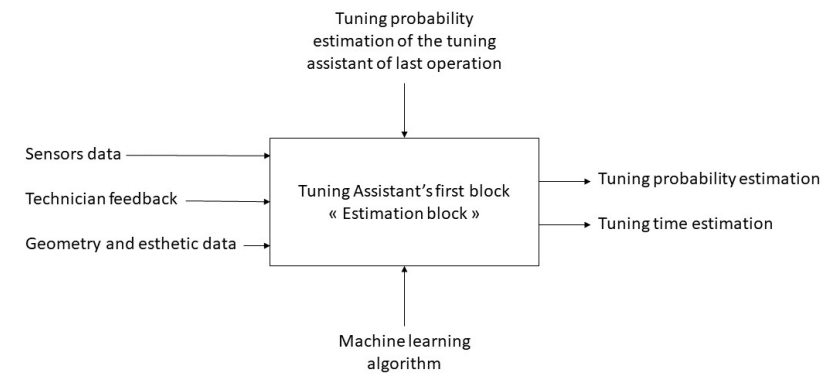

Fig. 1. IDEF0 of the first block of the tuning assistant component.

\subsection{Predictive maintenance with machine learning}

All the production machines need to be repaired regularly, it is not rare to see highly stressed machines needing maintenance multiple times a month. Nowadays this reality is more obvious than ever with the increasing complexity of the equipment. Production time's losses added with maintenance cost can be very harmful to a company. Predictive maintenance is a strategy which, as illustrated in figure 3, aims to remove the time where the broken machine is waiting for 


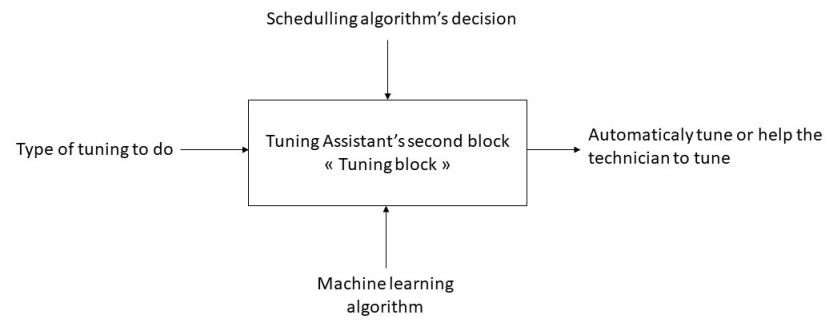

Fig. 2. IDEF0 of the second block of the tuning assistant component.

reparation by predicting and preventing the failures before their occurrence.

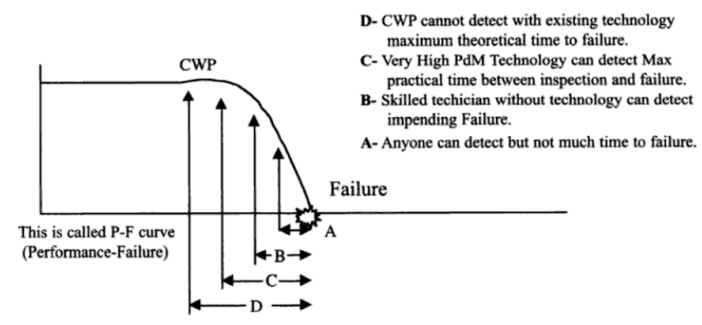

Fig. 3. The predictive maintenance strategy aim to detect early signals to predict failure and launch maintenance before the machine fail. CWP stand for critical wear point. [9]

This strategy is quite old [11], it enters in the preventive maintenance strategy group, with for instance the planned maintenance strategy which plans the maintenance in function of suppliers' predictions. The particularity of Predictive maintenance is that machines' health is monitored in real time and future failures predicted, using multiple sensors and machine learning algorithms.

To implement it, relevant data have first to be identified. Usually, supervised algorithms are used for predictive maintenance, and so, labeled training data set have to be furnished which assume to clearly know which information to measure and when the production machine will fail. Several articles [1] [2] describe the use of unsupervised machine learning algorithms permitting to detect the failure by measuring unusual behaviors, therefore compensating a possible lack of knowledge against a loss of accuracy. Actually, even if there are some articles looking at other types of data, such as acoustic signature [5],the most commonly studied feature is the vibration. Other information could be studied such as temperature measurement, flow measurements, electrical analysis, thickness measurement analysis, efficiency analysis, analysis of positions and alignments, etc [8]. When the data is accessible, a machine learning algorithm has to search a 
possible relation between failures and measured information. Encountering the right algorithm is at the present time a hot topic, Pushe et al. [16] proposed a way to pre-process the data, enabling anomalies to be detected more easily. There are a lot of different algorithms [7] [13] that are proposed by the literature, but there is no consensus on which one is the best in which case.

In this approach predictive maintenance is the Second fundamental component. In the classical approach it only takes data as input. In our approach, on top of data is added the estimated probability that tuning has to be done. This input is fed by tuning assistant block. As explained before, tuning assistant is not machine-centered but product centered, it detects from machine's data potential product nonconformities. Those nonconformities can sometime be an alert for some type of machine failure. Moreover, the Tuning assistant can also use, as input, the conclusions of previous tuning assistants, therefore it pre-process for the predictive maintenance algorithm a broader amount of data. The Predictive maintenance component outputs are firstly a vector of the estimation percentage of all the different failures, secondly a vector of estimation of the time that it will take to repair those failures.

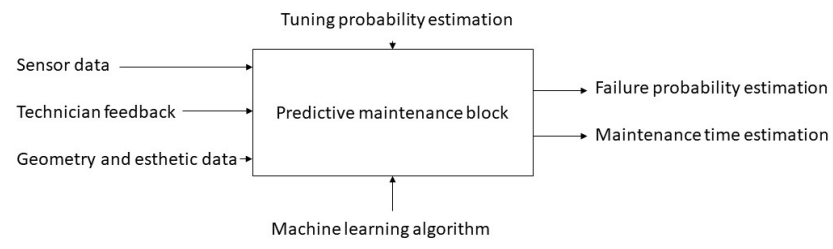

Fig. 4. IDEF0 of the predictive maintenance component.

\subsection{Automatic scheduling under high uncertainty}

In this approach the last component is the automatic scheduling algorithm. It is the brain of the model, which takes into account uncertainty and decide to launch and schedule maintenance operation, authorizes machine tuning and plan changeover. Its Input are multiples, It takes all the outputs from the two others components that are predictive maintenance and tuning assistant's estimation block. Moreover, it takes all the classical information provided to scheduling algorithm such as production order, available resources, etc..

To decide to launch a maintenance, it computes the estimation of failures and the estimation of the time needed to correct those failures which also contain a lot of uncertainties. Taking into account potential tuning needs, the production pressure and more, the algorithm evaluates the risk and decide or not to plan maintenance. To decide if a machine need to be tuned, it uses the estimate of percentage of tuning and the estimation of the time it will take. Again taking into account other information such as production pressure or available resources, it 
decides or not to launch or to plan a tuning request. Doing so it sends the request to the second block of the tuning assistant.

Using all this information the automatic scheduling algorithm has to deal with a lot of uncertainty, thanks to existing algorithms which can optimize this kind of problems.

Automatic scheduling is a well known field, a lot of algorithm exist which model the problem, solve it and evaluate the solution to ensure its quality. A lot of those solutions are described by Manuel Dios in his review [6]. Even if we know how to include uncertainty into mathematical model such as two-stage stochastic programming, parametric programming, fuzzy programming, chance constraint programming, robust optimization techniques, conditional value-atrisk, and other forms of risk mitigation approaches [14], doing optimizing under high uncertainty is still challenging.

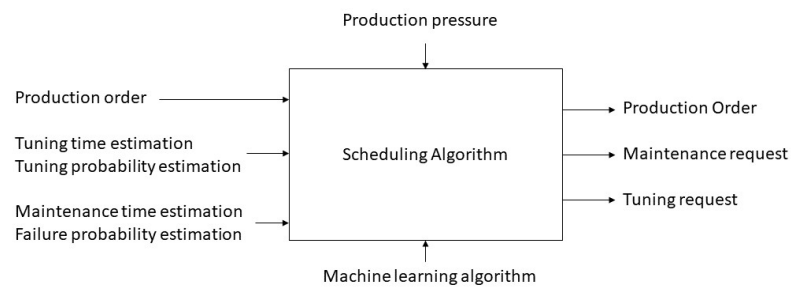

Fig. 5. IDEF0 of the automatic scheduling algorithm.

\subsection{Framework}

The approach proposed in this study, aims at integrating those three different technologies, i.e. product-centered tuning assistant, machine-centered predictive maintenance and finally production-centered automatic scheduling in a unique solution. As each one of them carries a lot of ambition, a huge effort is currently undertaken by the community in order to better understand them and so their implementation by the industry is only a few years away. However, no framework have been yet published to merge those technologies.

Going to the description of the framework, the first block is the tuning assistant which increases the productivity of the machine by detecting when to tune the machine and by tuning it automatically whenever is possible. It takes as input all the output/conclusions of the previous tuning assistant, of the same production chain. The second one is the predictive maintenance block which increases the production capability by detecting when to do maintenance on the machine. It can use information from the tuning assistant to understand the link between product unconformity and predicted future failure. The robust automatic scheduling algorithm can use all this information to optimize, when to 
do maintenance, when to tune the machine and to schedule production orders. For each possible tuning or failure, the two first blocks will give a percentage of chance of happening, as well as a time estimation to repair/correct the problem. With all of this this last block will do the optimal choice in term of production optimization. The block diagram in fig 6 illustrates how these three technologies work together and communicate with their environment.

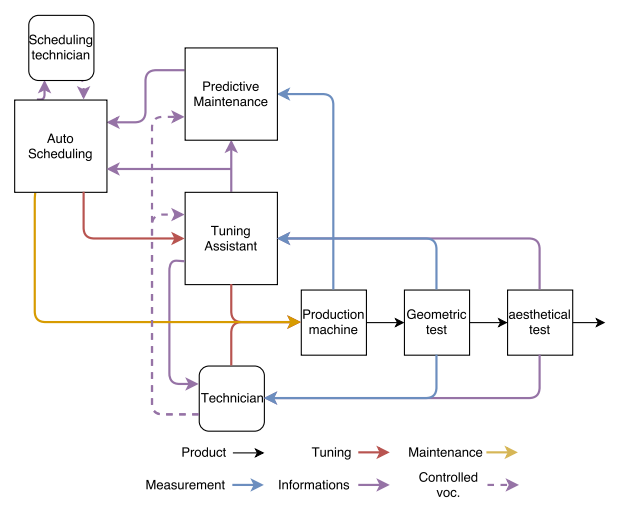

Fig. 6. Suggested approach to industry 4.0 .

\section{Discussion and conclusion}

The approach presented in this paper combine three ambitious technologies, i.e. tuning assistant, predictive maintenance and automatic scheduling algorithm, and it is now implemented in a case study of a high-end production company. Those technologies seem at first to be very different, but we theoretically found out that they can be very complementary. The first layer composed by tuning assistant and predictive maintenance is very challenging to implement in industrial study case. To be efficient machine learning technologies need a lot of labeled data. However, failure happen seldom and so gathering the theoretically good amount of data is not easily possible. Nowadays, this is one of the biggest limitation. Nonetheless, some solution are studied like on-line un-structured algorithm to tackle this challenge.

None of those are mastered, we still have a long journey to reach the final objective called the principle of digital twin. Due to the significant potential of the proposed approach significant, further research on the subject should be carried out to test, qualify and improve this solution.

Finally the macro solution merge three solutions that will reshape production floors such as machine oriented, product oriented and production oriented. An optimal production floor can be defined with those three ideas : Machine producing, Product conform and Production optimized. 


\section{References}

1. Amruthnath, N., Gupta, T.: Fault class prediction in unsupervised learning using model-based clustering approach

2. Amruthnath, N., Gupta, T.: A research study on unsupervised machine learning algorithms for early fault detection in predictive maintenance. In: 5th International Conference on Industrial Engineering and Applications (2018)

3. Author, A.A., Author, B.B., Author, C.: Title of article. Title of Journal 10(2), 49-53 (2005)

4. fact0r Consortium, Z.: Zero defect manufacturing strategies toward on-line production management for european factories (2016)

5. Darius, Ş.M., Florin, B.C., Marius, B., Edit, T.K., Mihai, P.R.: Maintenance planning of the sewing needles of simple sewing machines

6. Dios, M., Framinan, J.M.: A review and classification of computer-based manufacturing scheduling tools. Comput. Ind. Eng. 99(C), 229-249 (Sep 2016), https: //doi.org/10.1016/j.cie.2016.07.020

7. Grall, A., Dieulle, L., Berenguer, C., Roussignol, M.: Continuous-time predictivemaintenance scheduling for a deteriorating system. IEEE Transactions on Reliability 51(2), 141-150 (Jun 2002)

8. Keith Mobley, R.: An introduction to predictive maintenance / r. keith mobley (06 2018)

9. Levitt, J.: complete guide to prevent and predictive maintenance. Industrial Press (2003)

10. Liu, Q., Dong, M., Chen, F.: Single-machine-based joint optimization of predictive maintenance planning and production scheduling. Robotics and ComputerIntegrated Manufacturing 51, 238-247 (2018), https://www. scopus.com/inward/ record.uri?eid=2-s2.0-85043314559\&doi=10.1016\%2fj.rcim. 2018.01.002\& partnerID $=40 \& \mathrm{md} 5=\mathrm{ab} 66 \mathrm{baac} 39 \mathrm{~b} 0 \mathrm{cec} 96 \mathrm{c} 0063206 \mathrm{eb} 1 \mathrm{~d} 712$, cited By 0

11. Mobley, R.K.: An introduction to predictive maintenance. Butterworth-Heinemann (2002)

12. Raabe, H., Myklebust, O., Eleftheriadis, R.: Vision based quality control and maintenance in high volume production by use of zero defect strategies. Lecture Notes in Electrical Engineering 451, 405-412 (2018), https://www. scopus . com/inward/ record uri?eid=2-s2.0-85042218260\&doi=10.1007\%2f978-981-10-5768-7_43\& partnerID=40\&md5=1c88d96d94d44a76f369d37a721303d9, cited By 0

13. Sipos, R., Fradkin, D., Moerchen, F., Wang, Z.: Log-based predictive maintenance. In: Proceedings of the 20th ACM SIGKDD International Conference on Knowledge Discovery and Data Mining. pp. 1867-1876. KDD '14, ACM, New York, NY, USA (2014), http://doi.acm.org/10.1145/2623330.2623340

14. Verderame, P.M., Elia, J.A., Li, J., Floudas, C.A.: Planning and scheduling under uncertainty: A review across multiple sectors. Industrial \& Engineering Chemistry Research 49(9), 3993-4017 (2010), https://doi.org/10.1021/ie902009k

15. Wang, K.S.: Towards zero-defect manufacturing (zdm) - a data mining approach. Advances in Manufacturing 1(1), 62-74 (Mar 2013), https://doi.org/10.1007/ s40436-013-0010-9

16. Zhao, P., Kurihara, M., Tanaka, J., Noda, T., Chikuma, S., Suzuki, T.: Advanced correlation-based anomaly detection method for predictive maintenance. In: 2017 IEEE International Conference on Prognostics and Health Management (ICPHM). pp. 78-83 (June 2017) 